\title{
Visualization of Multiple Flame Interactions: Appearance Structure and Combustion of LPG-Air Premixed Laminar Flames
}

\author{
U. Makmool, S. Jugjai, and S. Tia
}

\begin{abstract}
Interaction of multiple premixed laminar flames was studied by visualizations of the modified flame structures. Typical line-of-sight flame chemiluminescence image and spatial resolved $\mathrm{OH}$ distribution by means of planar laser-induced fluorescence (OH-PLIF) technique were applied for these observations. The premixed flames of liquefied petroleum gas (LPG)/air mixture with three inline nozzles were established to simulate the practical flame characteristics produced by the practical cooking burners. The obtained results are compared as a function of primary equivalence ratio $(\Phi)$ and inter-distance $\left(S / D_{0}\right)$ between nozzles. Effect of $S / D_{0}$ and $\Phi$ on the multiple premixed flame structures is well understood via the clarifying reaction zone distribution, which is in-situ visualized by OH PLIF technique. $S / D_{0}$ has a strong effect on interactions between flames, resulting in either flame enhancement or flame inhibition, depending on $\Phi$. $\mathrm{CO}$ and $\mathrm{NO}_{\mathrm{x}}$ emissions were measured in order to confirm the combustion performance of the multiple flames. It is recommended that the in-situ visualization is the focus for a study of the flame. This will help to avoid misunderstanding of the real combustion as it can be occurred by using the line-of-sight observation technique.
\end{abstract}

Index Terms-Partially premixed flame, flame structures, reaction zone, $\mathrm{OH}-\mathrm{PLIF}$, interaction between flames.

\section{INTRODUCTION}

A premixed flame is widely used for many combustion systems because it can produce high temperature from flames with low pollutant emissions. Regarding its wide application on domestic utilization in cooking stoves, multiple jets of the laminar premixed flames are produced for the heating processes. Even though the amount of gas used by each stove is small, more than $40 \%$ of the total consumption of LPG (liquefied petroleum gas) in Thailand is used by this type of burner in the residential sector [1]. Thus, the improvement of thermal efficiency and emissions of cooking stoves operating with the premixed flame is a key target for present and future performance regulation. Many previous studies regarding single or multiple premixed flame jets have focused on the

Manuscript received March 26, 2014; revised June 27, 2014. This work was supported by the Joint Graduate School of Energy and Environment (JGSEE) and the National Research Council of Thailand (NRCT).

U. Makmool is with the Pilot Plant Development and Training Institute, King Mongkut's University of Technology Thonburi, Bangkok, Thailand (e-mail: usa.mak@kmutt.ac.th).

S. Jugjai is with Department of Mechanical Engineering, Faculty of Engineering, King Mongkut's University of Technology Thonburi, Bangkok, Thailand (e-mail: sumrueng.jug@kmutt.ac.th).

S. Tia is with Department of Chemical Engineering, Faculty of Engineering, King Mongkut's University of Technology Thonburi, Bangkok, Thailand (e-mail: suvit.tia@kmutt.ac.th). heat transfer process from flames to the target, i.e. flame impingement has been extensively studied. Both heat transfer characteristics (which is implied by heat flux distribution or local/averaged Nusselt number), and pollutant emissions resulting from impinging flame jets were experimentally studied as a function of different key parameters. These include Reynolds number, equivalence ratio, nozzle-to-plate distance, distance between the adjacent burners [2], and inclination angles [3]. These parameters influence flow pattern, which creates distinctly different flame shapes Remie et al. [3] presented a simple relation that predicts the parameters of the burnt gas flow of a flame jet, Bunsen-type flame after expansion over the flame front. They stated that the parameters of the burnt gas flow, i.e. jet velocity and jet width, are important to estimate the heat transfer from flame jets to products. Thermal performance parameters and dynamic properties of the flow field at a flame impingement area, i.e. velocity magnitude, turbulent intensity, vorticity and strain rate, were reported [4]. These confirm the correlation between thermal efficiencies and flow fields which are controlling structures of the producing flame jets.

Extensively, line-of-sight flame visualization techniques, e.g. direct photography of typical visible flame or imaging chemiluminescence emission of the combustion species, i.e. $\mathrm{OH}, \mathrm{CH}$ and $\mathrm{C} 2$ were performed [5], [6]. However, the emission intensity was integrated along a viewing line. Different parts of the flame, such as the primary and the secondary combustion zones and the inter-zonal region, were observed. Radiation components were not separated. In-situ visualization technique was used to solidly clarify the real combustion situation in flames.

This work investigates the variation of the main reaction zone as a function of the key parameters, i.e. primary equivalence ratio and inter-port spacing. Laminar premixed LPG-air multiple flame structure was observed using both typical line-of-sight observation and $\mathrm{OH}$ planar laser-induced fluorescence (OH PLIF) techniques. The OH PLIF was introduced to acquire the in-situ, two-dimensional image of the main reaction zone (i.e., regions containing high concentration of $\mathrm{OH}$ species). Precisely revealed reaction zone distribution is expected. This is as a result of the interaction between the adjacent flame jets to further improve burner performance.

\section{Methodology}

\section{A. Test Burner and Facilities}

The test burner was an assembly of a three-vertical-nozzle tube with an in-line arrangement. Each nozzle tube was made 
of a $160 \mathrm{~mm}$ stainless steel with a $7 \mathrm{~mm}$ inside diameter $(D)$ and an $8 \mathrm{~mm}$ outside diameter $\left(D_{\mathrm{o}}\right)$, which is sufficient for a fully developed mixture flow before exit. The nozzle tube assembly was placed on a fixture capable of adjusting the inter-distance $S$ between the nozzle centers. Multiple free flame jets with equal mixture flow rate and pressure drop across the rubber host could be produced by adjusting control valves connected to each nozzle tube inlet.

Compressed air was introduced as the primary air to the test burner, whereas the secondary, ambient air was naturally entrained by flames. The liquid-phase LPG (composed of roughly $70 \%$ and $30 \%$ by volume of propane and butane, respectively) was evaporated by a vaporizer before being supplied to the mixing chamber in order to keep uniformity of gas composition and pressure. $\Phi$ (defined by a ratio of the stoichiometric air required for complete combustion to the primary air supplied) was varied by decreasing the primary air flow rate from the stoichiometric air to fuel ratio, i.e. $\Phi$ $=1.02$, to a fuel rich condition at $\Phi=1.72$, which corresponds to Reynolds number (based on properties of the primary air) ranging from 500 to 350 , respectively. Three inter-distances were set at $S / D_{\mathrm{o}}=1.0,1.5$, and 2.0. The firing rate was kept constant at $0.45 \mathrm{~kW}$ (i.e., $0.15 \mathrm{~kW}$ for an individual nozzle). The flow rate of air was calibrated by a wet-type gas flow meter with an accuracy of 0.01 liters which was also used to measure the LPG gas flow rate.

\section{B. Imaging of Flame Structure}

The flames were captured by two different imaging techniques. The line-of-sight observation technique via the imaging of flame chemiluminescence was introduced. The spatially resolved imaging was carried out by means of the $\mathrm{OH}-\mathrm{PLIF}$ technique. The imaging procedures to acquire the image types were the following:

\section{Line-of-sight Imaging of Flame Chemiluminescence}

To acquire flame chemiluminescence intensity, the ICCD camera, a combination of the intensifier (Hamamatsu C9016 series) and the CCD camera (Dantec HiSense MkII) equipped with the UV lens (Niker $60 \mathrm{~mm}$, f 2.8) was used to amplify and collect the chemiluminescence of the flames, respectively. The intensifier unit was needed to increase the signal-to-noise ratio of the chemiluminescence which was very weak for a premixed flame. The light emission which was imaged was a result of the chemical excitation of molecular production at the electronic state. In hydrocarbon oxidation, major emitters are $\mathrm{OH}^{*}, \mathrm{CH}^{*}, \mathrm{C}_{2}{ }^{*}$, and $\mathrm{CO}_{2} *$ [7], [8]. The capturing, i.e. the exposure time, was done continually along the width of $10 \mathrm{~ms}$.

\section{Spatially Resolved Imaging of $\mathrm{OH}-\mathrm{PLIF}$}

The PLIF experimental set-up is shown schematically in Fig. 1. The system components and the mechanism to produce the UV laser sheet to excite the $\mathrm{OH}$ species in flame were explained in detail in Makmool (2011) [9]. The UV laser beam of wavelength $282.6 \mathrm{~nm}$ and the maximum energy per pulse of $8 \mathrm{~mJ}$ was produced. The energy pulse monitor (EPM) was mounted between the laser head and the light sheet formation optic system. Then, it was transformed to a thin sheet with the height fixed at $35 \mathrm{~mm}$. The illuminated plane was cut off at the section along the centerline of the multiple burners that was normal to the camera. Thus, the two-dimensional distribution of fluorescence emission of the excited $\mathrm{OH}$ could be observed in the flames.

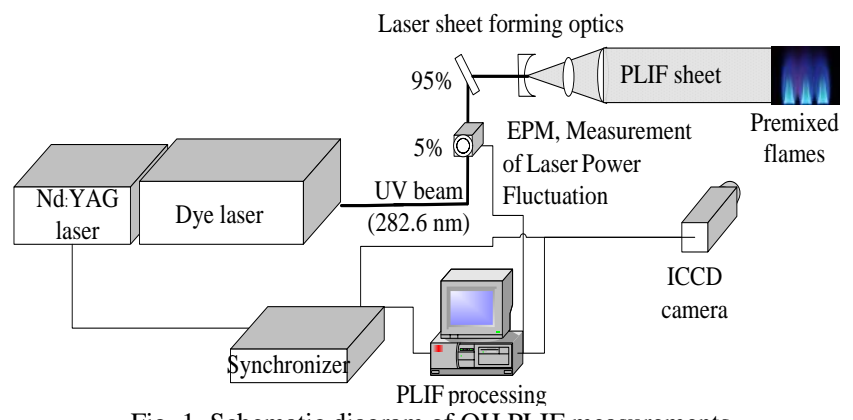

Fig. 1. Schematic diagram of OH PLIF measurements.

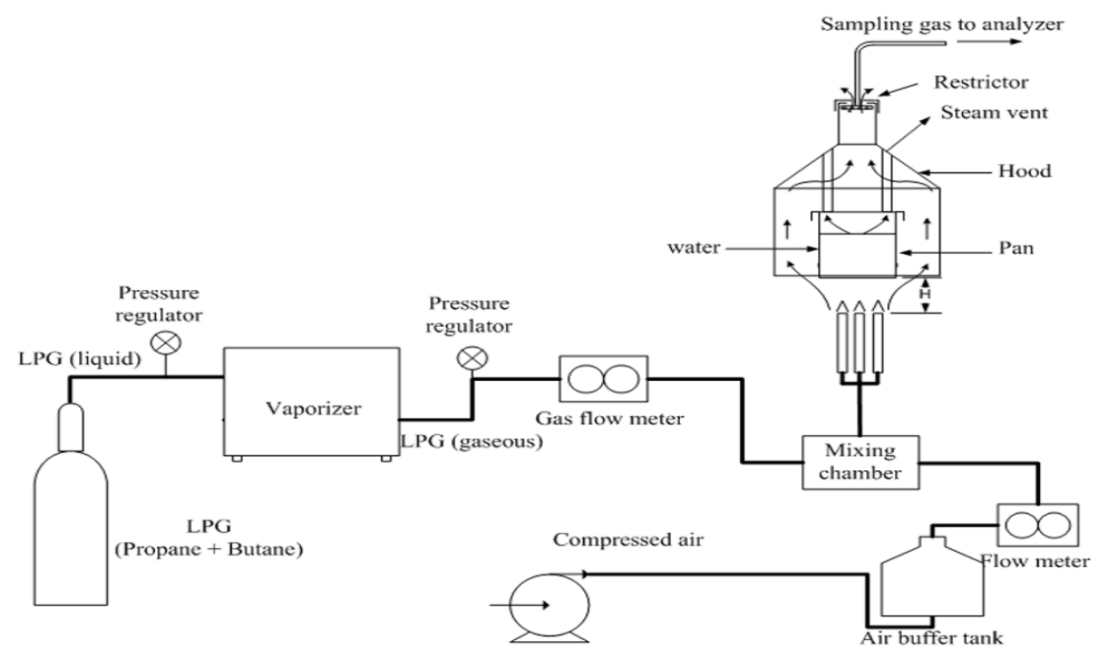

Fig. 2. Schematic diagram of exhaust gases measurements.

The LIF signals of the $\mathrm{OH}$ fluorescence emission were detected with an ICCD camera. The optical interference filter of $313 \pm 25 \mathrm{~nm}$ was coupled with the UV lens (Niker $60 \mathrm{~mm}, \mathrm{f}$ 2.8 ), installed in front of the ICCD. This allowed only the selected fluorescence to pass, blocking undesirable ambient light (reflection and stimulated emission). The intensifier gate width was set at 1,000 ns. In addition, the raw OH-PLIF image was subtracted from the background image to completely suppress any luminosity from flames as well as artificial lighting in the test room. One hundred instantaneous images were averaged and reported in the result as the mean of the OH-PLIF images of all case studies. The radical 
absorption was not corrected due to the relatively small field of visualization.

\section{E. $\mathrm{CO}$ and $\mathrm{NO}_{x}$ Measurements}

The pollutants emission test was guided by the European testing standards for gas heated catering equipment [10], [11]. A standard hood was used to collect exhaust gases to the analyzer with the minimizing of dilution effects (Fig. 2). The pan was filled with water and covered by a hood for collecting the exhaust gases separately from the generated steam, which was vented through the vertical channels integrated into the hood. The exhaust gases were then sampled by a probe which connected to an emission analyzer at the hood exit. Emission analysis was carried out by using the Messtechnik Eheim model Visit01L, which is a portable emission analyzer designed specifically for quasi-continuous measurement. The measuring ranges of the analyzer were 0-10,000 ppm for CO and $0-4,000 \mathrm{ppm}$ for NO with the measuring accuracy of $\pm 5, \pm 4 \mathrm{ppm}$ (from the measured value), respectively, and resolution of $1 \mathrm{ppm}$. Repeated measurement showed an uncertainty of about $10 \%$ for the species concentrations. Combustion was checked within 15 minutes after ignition, and the concentrations of $\mathrm{CO}, \mathrm{NO}$ and $\mathrm{CO}_{2}$ were measured. To achieve adequate accuracy, dilution by ambient air was arranged so that the $\mathrm{CO}_{2}$ content in the sample of the products of combustion was at least $2 \%$. This was done by adjusting an opening area of the restrictor installed at the hood exit.

\section{RESULTS AND DISCUSSION}

\section{A. Flame Appearances}

Fig. 3a and Fig. 3b show the corresponding flame chemiluminescence images and the $\mathrm{OH}$ PLIF images of a single flame, respectively. The equivalence ratio of 1.02, 1.20, 1.28 , and 1.71, from the left to the right, was increased by decreasing primary air flow rate. These single flames images were recorded and presented in order to be used as the reference flame structures, which do not factor in the interaction between the nearby flames.

\section{B. Line-of-sight Chemiluminescence Images of the Single Flame}

Fig. 3a shows the corresponding line-of-sight images of chemiluminescent flame. The color contour represents the chemiluminesence intensity; the highest to the zero one are color from red to dark blue, respectively.

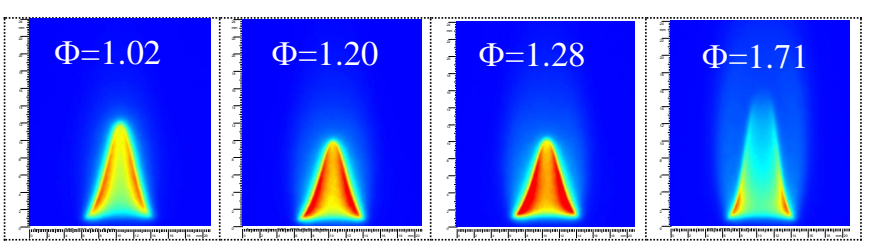

(a) Typical line-of-sight chemiluminescence images.

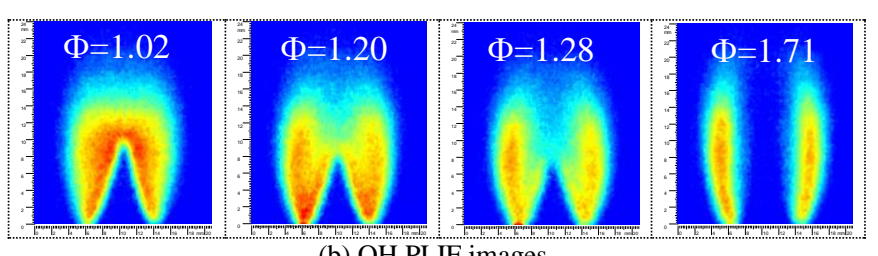

(b) OH PLIF images.

Fig. 3. Structure of the single premixed flames.
As shown in these images, for the fully premixed flame at $\Phi=1.02$, the inner cone is slender in shape but is diluted in flame chemiluminesnce intensity. Increasing $\Phi$, the inner premixed cone length decreases while flame chemiluminescence intensity increases. The maximum intensity was reached at $\Phi=1.28$ (Fig. 4), corresponding to when the minimum premixed cone (Fig. 5) was achieved. This may infer that the maximum burning rate is achieved at this equivalence ratio. Increasing equivalence ratio to $\Phi$ $=1.71$, the premixed cone length increases and its chemiluminescence signal decreases (see Fig. 4 and Fig. 5).

As shown the chemical reactions are taking place closer to the burner rim (see Fig. 3a) rather than around the premixed cone, due to an insufficient amount of premixed air. Near the burner rim, secondary air entrainment occurs most effectively. This is owing to a high velocity of the emerging jet induces the stationary surrounding air.

\section{OH PLIF Images of the Single Flame}

Fig. $3 \mathrm{~b}$ shows the corresponding images of $\mathrm{OH}$ PLIF. The $\mathrm{OH}$ PLIF contours are used as a tool to indicate the oxidation zone. In contrast to the line-of-sight images, the OH PLIF signal was not detected inside the premixed cone. This is due to the fact that combustion does not take place there. The $\mathrm{OH}$ region distribution extends from the outer side of the premixed cone to the diffusion layer. At the stoichiometric flame, i.e. $\Phi=1.02$, the $\mathrm{OH}$ region relies uniformly beyond the premixed cone. The highest intensive zone appears around the tip of the premixed con, due to a highly preheating effect obtained by diffusion of the high temperature intermediate species from both sides of the apex. Thus, the fuel oxidation process within this location is enhanced. As $\Phi$ increases (i.e., $\Phi=1.20$ and $\Phi=1.28$ ), the $\mathrm{OH}$ region moves away from the inner cone to the secondary combustion zone and a double flame structure (i.e., premixed flame plus diffusion flame) is established. In a fuel-rich mixture ( $\Phi=$ $1.71)$, the $\mathrm{OH}$ PLIF structure is nonpremixed-like flame structure, i.e., the premixed cone does not exist.

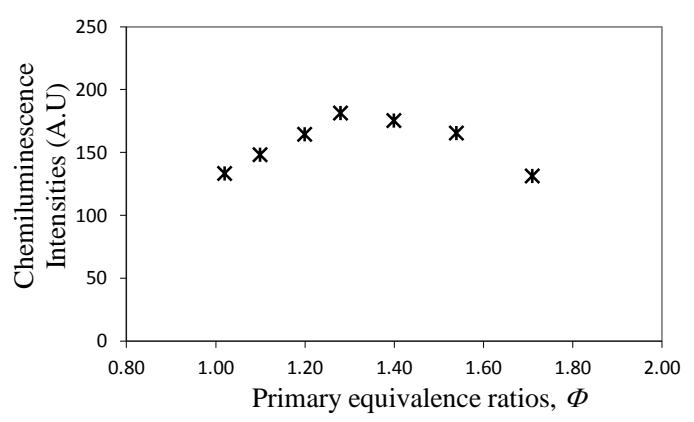

Fig. 4. Effect of $\Phi$ on the maximum chemiluminescence intensity.

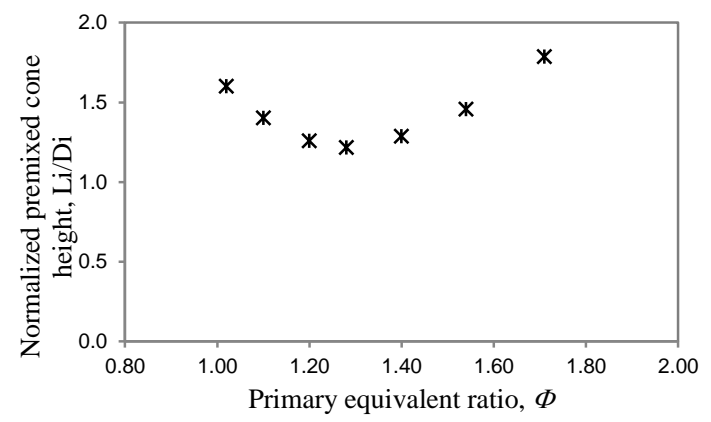

Fig. 5. Effect of $\Phi$ on the premixed cone length. 
Due to the fact that primary air concentration is too low for fuel oxidation, burning velocity is relatively low, long flame length is established. High OH PLIF intensity occurs in the outer region, where fuel and air are reached each other. Thus, the oxidation reaction is controlled by diffusion of the fuel-rich mixture into the surrounding air.

\section{Multiple Flame Interactions}

To investigate the effect of multiple flame interaction on flame structure, a modification of flame shape was determined by means of a change in the premixed cone length In Fig. 6, premixed cone length of the central flame of the three in-line multiple flames $\left(L_{\mathrm{m}}\right)$ was measured and compared with that of a single flame $\left(L_{\mathrm{s}}\right)$, with no nearby flames. It was presented in term $L_{\mathrm{m}} / L_{\mathrm{s}}$. In this comparison, it shows an enhanced burn rate of the multiple flames because the premixed cone length was reduced compared with that of the single flame (i.e., $L_{\mathrm{m}} / L_{\mathrm{s}}<1$ ). The richer flame results in a stronger flame interaction, i.e. the larger reduction in flame length occurred, especially at $S / D_{o}=1.0$. The reduction in flame length may be due to the strong self-preheating effect which occurred when the flames were placed close to each other. The burn rate was enhanced, and the central premixed cone length was reduced.

Fig. 7a and Fig. 7b, respectively, show the corresponding chemiluminescence and OH PLIF images of the multiple flames of different inter-distances, i.e., $S / D_{o}=1.0,1.5$, and 2.0 at the same equivalence ratio of $\Phi=1.28$. In Fig. 7a, a significant difference in intensities of the chemiluminescence signals of the flames was not observed. However, at $S / D_{o}$ $=1.0$, the central flame yielded a slightly higher chemiluminescence intensity and smaller premixed cone as compared with those of the nearby ones.

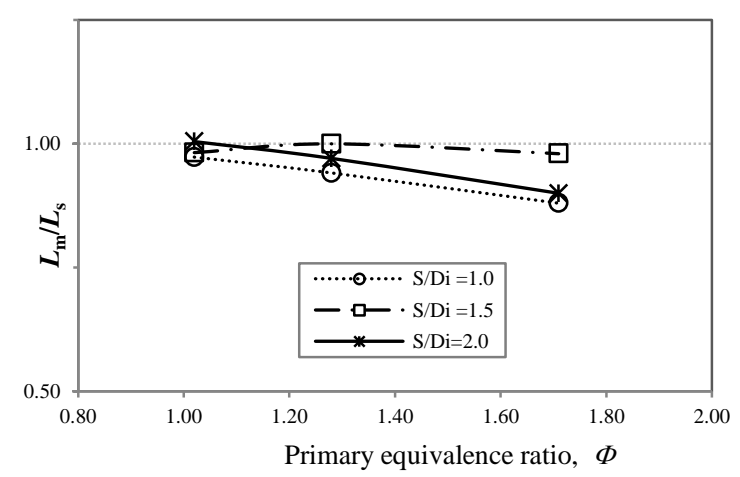

Fig. 6. Effect of $S / D_{o}$ on reduction of the premixed cone length.

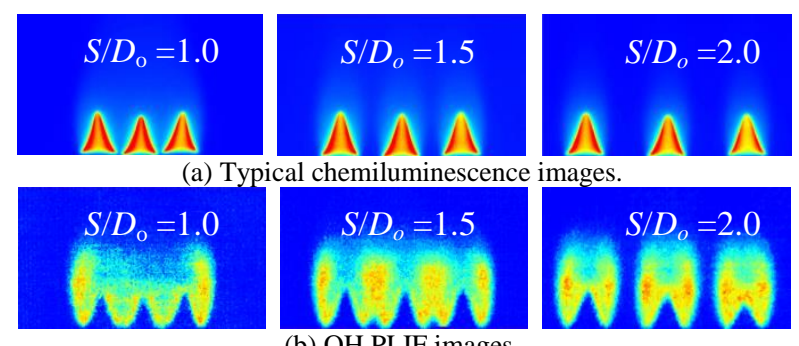

(b) OH PLIF images.

Fig. 7. Multiple flames appearance at $\Phi=1.28$.

At this spacing, the combustion may be significantly improved because of the intense exchange of heat and reactive species between the nearby flames resulting in a greater reduction of premixed cone length (as observed in Fig.
6). Flames at the other greater inter-distances yield no significant difference in either the chemiluminescence intensity or the premixed cone length.

In contrast to the line-of-sight chemiluminescence images, the OH-PLIF images (Fig. 7b) show vast differences in the structures of the three flame spacing. At $S / D_{o}=1.0$, the flame produces a non-uniform distribution and less intense $\mathrm{OH}$ PLIF structure. Due to a relative decrease in OH PLIF intensity, it seems as if the oxidation via $\mathrm{OH}$ distribution is inhibited especially at the central area of the multiple flames.. It is indicated that a poor or incomplete combustion occurs inside the central region of the multiple flames. This phenomenon is in the opposite trend to the observation of flame chemiluminescence image, as previously explained.

At spacing of $S / D_{o}=2$, three independent, cool, inner cones covered with their own outer cones of the $\mathrm{OH}$ species are obtained. The interaction between the nearby flames was not observed, i.e. the OH PLIF structure was not significantly changed compared with that of the single flame at the same equivalence ratio (see Fig. 3).

An interesting phenomenon is revealed with multiple flames at an intermediate inter-distance of $S / D_{o}=1.5$. At the outer region of each individual flame, the $\mathrm{OH}$ species merge into a single, large, global outer cone of the OH PLIF. Higher intensities with more uniform distribution of OH-PLIF structure were produced as compared with that of the other $S / D_{o}$.

These results show that the interpretation of flames based on the chemiluminescence images alone can lead to misunderstanding of the related combustion phenomena.

\section{E. CO and NOx Emissions}

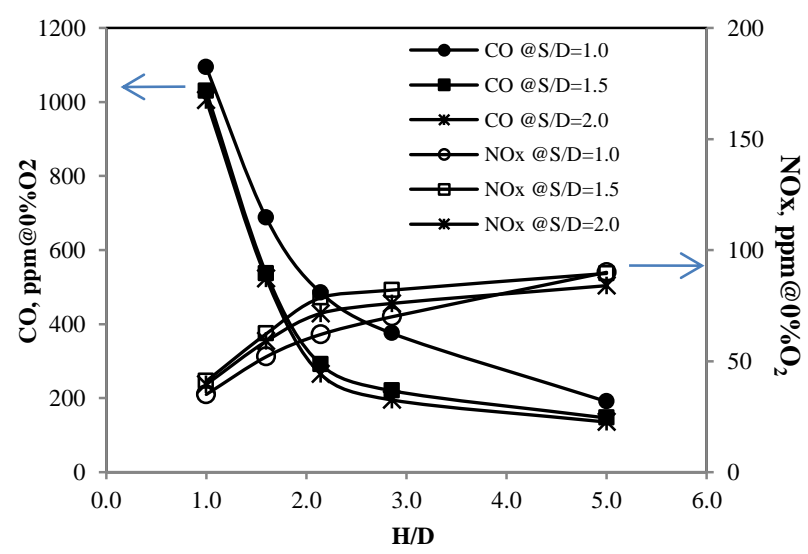

Fig. 8. Effect of $S / D_{\mathrm{o}}$ and heating height on emission at $\Phi=1.28$.

Fig. 8 shows corresponding combustion performances in terms of $\mathrm{CO}$ and $\mathrm{NO}_{x}$ emissions of the impinging multiple flames at differing heating height. In this case, the distance of impingement surface (i.e., the water-filled pan) from the burner exit was varied and normalized by the nozzle diameter $(H / D)$. This effect was also investigated as it will be applied to the household cooking burner. The result shows that the closest multiple flames $\left(S / D_{o}=1.0\right)$ yield the highest $\mathrm{CO}$ emissions and the lowest $\mathrm{NO}_{x}$ emission. Seemingly, the poorest combustion was achieved compared with other flame spacings. By this combustion measurement, the result not agrees with observation by the typical line-of-sight flame image. On the other hand, it was well correlated with the in-situ $\mathrm{OH}$ PLIF image in which the poor $\mathrm{OH}$ distribution 
was observed for the multiple flames at $S / D_{o}=1.0$ (Fig. 7b). Increasing $S / D_{\mathrm{o}}$ decreased $\mathrm{CO}$ emission but increased $\mathrm{NO}_{\mathrm{x}}$ emission because the larger amount of secondary air is entrained through the free space between each adjacent burner.

Regarding the effect of heating height, at $H / D=1.0$, the flame jets were emerging from the burners with relatively high velocities and interrupted by the presence of impingement surface downstream. Hence, the residence time of combustion is shortened and the flames are strongly quenched. Therefore, significantly high $\mathrm{CO}$ emission and low $\mathrm{NO}_{\mathrm{x}}$ was measured for all considered $S / D_{\mathrm{o}}$.

At $H / D>1$, the difference in combustion performances of both $\mathrm{CO}$ and $\mathrm{NO}_{\mathrm{x}}$ emission, by the influent of $S / D_{\mathrm{o}}$, was revealed due to the fact that combustion efficiency becomes dominant. As $H / D$ increased, $\mathrm{CO}$ emission decreased and $\mathrm{NO}_{\mathrm{x}}$ emission increased. This is explained by the fact that an increase in $H / D$ will reduce the amount of cold mixtures which will impinge to the surface and increase the combustion residence time. It also increases the amount of the secondary air entrainment. In contrast to the CO emissions, the highest $\mathrm{NO}_{\mathrm{x}}$ emission is achieved at $S / D_{\mathrm{o}}=1.5$ and at any given $H / D$. It can be inferred that the highest flame temperature might be achieved; hence, high thermal- $\mathrm{NO}_{\mathrm{x}}$ was produced. Compared to the flame at $S / D_{\mathrm{o}}=2.0$, where the individual flame in the group is freely combustible as the lowest concentration of $\mathrm{CO}$ gases was detected, it seem as moving the flames closer to each other at $S / D_{\mathrm{o}}=1.5$, combustion enhancement was occurred. Even as CO emissions slightly increase, the higher flame temperature may be achieved owing to higher measurable $\mathrm{NO}_{\mathrm{x}}$ emission. At this flame spacing, interaction between the adjacent flames produces combustion recirculation and preheats surrounding air. Thus, it shows improved combustion efficiency. Furthermore, the oxidation reaction is distributed intensively inside the interaction regions of the nearby flames (Fig. 7b). On the other hand, combustion can be considered to be inhibited for the grouped flames with no gap, i.e. $S / D_{\text {o }}$ $=1.0$. Not only is the secondary air entrainment blocked, but the flames may also be quenched by the interference from nearby flames. Combustion efficiency decreases, yielding highest $\mathrm{CO}$ emission and lowest $\mathrm{NO}_{\mathrm{x}}$.

At $H / D=5$, all groups emit less CO. At the highest impingement, both $\mathrm{CO}$ and $\mathrm{NO}_{\mathrm{x}}$ emissions become identical. The flames are less inhibited and are more naturally burned. Combustion residence time and the amount of surrounding air increase high enough to complete the combustion.

\section{CONCLUSION}

OH PLIF technique was implemented with line-of-sight chemiluminescence imaging technique in order to capture flame appearances to study the affect of the interaction of multiple premixed liquefied petroleum gas (LPG)-air flames. The combustion was checked via measuring $\mathrm{CO}$ and NOx emission at differing inter-spacing between the flames. The following conclusions can be drawn from the studied results:

1) The flame at equivalence ratio of 1.28 emits maximum chemiluminescent intensity and corresponds to the smallest premixed cone length.
2) The interaction of the multiple flames significantly modified natural combustion of the individual flame. $S / D_{\text {o }}$ has a strong affect on interactions between flames, resulting in either flame enhancement or flame inhibition, depending on $\Phi$.

3) The OH-PLIF measurement was the most reliable technique to uncover the combustion situation existing in the flames. A clarifying reaction zones distribution was revealed and can be used for a better explanation of the effect of flame structure on emissions. Flame enhancement and inhibition were clearly observed, which were accessed with difficulty by means of the conventional line-of-sight imaging techniques.

4) Interpretation using only the appearance chemiluminescence structure is ambiguous and can lead to misunderstanding in the real combustion taking place in the flame. This can be explained by the fact that emission signals are line-of-sight integrated.

5) This study results in an understanding of the insight into the structure of the multiple premixed impinging flames. This may be useful in the future design a practical cooking burner.

\section{ACKNOWLEDGMENT}

This study is carried out in the Combustion Technology Laboratory (CBT), Pilot Plant Development and Training Institute (PDTI) at King Mongkut's University of Technology Thonburi (KMUTT). It is sponsored by the Joint Graduate School of Energy and Environment (JGSEE) and the National Research Council of Thailand (NRCT).

\section{REFERENCES}

[1] U. Makmool, "Improvement of thermal performance of LPG cooking burner: Applications of PIV," M. Phil Thesis, The Joint Graduate School of Energy and Environment, King Mongkut's University of Technology Thonburi (KMUTT), Bangkok, Thailand, 2005.

[2] U. Makmool, S. Jugjai, S. Tia, P. Vallikul, and B. Fungtammasan, "Performance and analysis by particle image velocimetry (PIV) of cooker-top burners in Thailand," Energy, vol. 32, no. 10, pp. 1986 , 2007.

[3] S. G. Tuttle, B. W. Webb, and M. Q. McQuay, "Convective heat transfer from a partially premixed impinging flame jet. Part I: Time-averaged results," Int. J Heat Mass Transfer, vol. 48, no. 7, pp. 1236, 2005.

[4] A. Arnold, R. Bombach, and A. Schlegal, "Quantitative measurements of $\mathrm{OH}$ concentration fields by two-dimensional laser-induced fluorescence," Appl. Phys. B, vol. 64, p. 579, 1997.

[5] R. Bombach, "Simultaneous visualization of transient species in flames by planar-laser-induced fluorescence using a single laser system," Appl. Phys. B, vol. 68, no. 2, p. 251, 1999.

[6] B. O. Ayoola, R. Balachandran, J. H. Frank, E. Mastorakos, and C. F. Kaminski, "Spatially resolved heat release rate measurements in turbulent premixed flames," Combust Flame, vol. 144, no. 1-2, p. 1, 2006.

[7] J. Kojima, Y. Ikeda, and T. Nakajima, "Basic aspects of $\mathrm{OH}(\mathrm{A})$, $\mathrm{CH}(\mathrm{A})$, and $\mathrm{C}_{2}(\mathrm{~d})$ chemiluminescence in the reaction zone of laminar methane-air premixed flames," Combust Flame, vol. 140, pp. 34-45, 2005.

[8] A. G. Gaydon, Spectroscopy of Flames, Wiley: New York, 1974.

[9] U. Makmool, S. Jugjai, S. Tia, Y. Laoonual, P. Vallikul, and B. Fungtammasan, "Laser-based investigations of flow fields and $\mathrm{OH}$ distributions in impinging flames of domestic cooker-top burners," Fuel, vol. 90, pp. 1024-1035, 2011.

[10] European Committee for Standardization, Specification for Gas Heated Catering Equipment- Part 1: Safety Requirements, EN 203-1:1992.

[11] European Committee for Standardization, Specification for Gas Heated Catering Equipment-Part 2: Rational Use of Energy, EN 203-2:1995. 
Usa Makmool received her $\mathrm{PhD}$ degree in energy technology at the Joint Graduate School of Energy and Environment, King Mongkut's University of Technology Thonburi (KMUTT), Bangkok, Thailand in 2012. She is now a researcher in the Combustion Technology Laboratory (CBT), Pilot Plant Development and Training Institute (PDTI) at KMUTT, Bangkok, Thailand. Her research interests are combustion analysis and measurements, and laser diagnostics in flows and combustion.

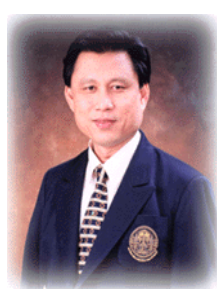

Sumrerng Jugjai received his M.Eng and D.Eng degrees in mechanical engineering at Tokyo Institute of Technology, Japan in 1988 and 1991, respectively. $\mathrm{He}$ is now a professor at Department of Mechanical Engineering, King Mongkut's University of Technology Thonburi. His research interests are combustion augmentation of fuels by porous media, combustion in internal combustion engines, pulsating combustion, heat transfer enhancement in furnace by porous media, emission regulation and testing methodology, applied thermodynamics.

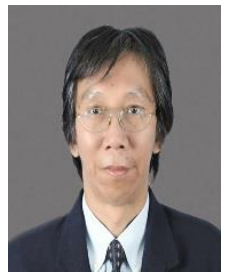

Suvit Tia obtained his bachelor's degree in chemical engineering and master's degree in energy technology from King Mongkut's Institute of Technology Thonburi. After obtaining his doctoral degree in energy technology from the Asian Institute of Technology (AIT) in 1990, Suvit joined the Department of Chemical Engineering, KMUTT, where he is currently an associate professor. Suvit has worked as a project leader on a number of projects, some of which are of regional and international nature. He was awarded as a 2005-2006 PTIT Fellow from the Petroleum Institute of Thailand for his excellent teaching record and contribution to improvement of education in the fields of petroleum. Suvit was appointed to be the deputy executive director of BIOTEC in November 2008 and is responsible for technology transfer and business development activities. 